\title{
ELEMENTOS DA DISTOPIA \\ EM VENTANIA BRAVA, DE LUIZ BRAS
}

ELEMENTS OF DYSTOPIA

IN VENTANIA BRAVA, BY LUIZ BRAS

Juliana Garcia Mendonça Hanke Alice Áurea Penteado Martha

Doutoranda em Letras pela Universidade Estadual de Maringá (UEM).

Professora Associada da Universidade Estadual de Maringá (UEM).

Via Atlôntica, Săo Paulo, n. 38, pp. 195-220, dez. 2020. 
Resumo: Neste texto, abordamos a narrativa Ventania Brava, de Luiz Bras, ambientada em 2090, procurando identificar e compreender a configuração da distopia no mundo narrado, especialmente em que medida sua estrutura estampa os temores da contemporaneidade, como crítica e alerta à sociedade. 0 relato destaca as ações de um governo ocupado por personagens adolescentes, sublinhando atitudes, desejos e expectativas dessa faixa etária, que vem ganhando cada vez mais visibilidade nos espaços sociais, notadamente como consumidora ávida de bens culturais. Refletimos, inicialmente, sobre a atuação do mercado do livro e a produção de bens culturais destinados aos jovens e adolescentes, destacando, na literatura juvenil, aspectos da narrativa distópica. Observamos, por fim, elementos que, na obra de Luiz Bras, configuram a distopia e proporcionam a seus leitores a reflexão acerca da realidade e a consequente experiência de participação como seres-no-mundo.

Palavras-chave: Ventania Brava, Luiz Bras, distopia. 
Abstract: In this text, we approach the narrative Ventania Brava, by Luiz Bras, set in 2090, seeking to identify and understand the configuration of dystopia in the narrated world, especially to what extent its structure prints the fears of contemporaneity, as critical and alert to society. The report highlights the actions of a government occupied by adolescent characters, underlining the attitudes, desires and expectations of this age group, which is gaining more and more visibility in social spaces, notably as an avid consumer of cultural goods. We initially reflected on the performance of the book market and the production of cultural goods for young people and adolescents, highlighting, in youth literature, aspects of dystopian narrative. Finally, we observe elements that, in the Luiz Bras' work, configure dystopia and provide to their readers the reflection about reality and the consequent experience of participation as beings-in-the-world.

Keywords: Ventania Brava, Luiz Bras, dystopia. 


\section{Introdução}

A partir do momento em que a relação entre a imprensa e a literatura se estreita, a posição do artista e de sua arte sofre alterações segundo postula BOURDIEU (2015) ${ }^{1}$. O pesquisador considera que a produção literária, como todas as demais instâncias artísticas, passa a depender de competências econômicas e sociais, as quais interferem, em maior ou menor grau, na vida do intelectual. Essa relação entre produção intensiva e literatura advém das modificações propiciadas pelo advento da indústria cultural, na década de 70, do século XX. 0 mercado editorial passa, então, a investir fortemente na arte de massa.

Ao considerar que o objetivo primeiro desse mercado é a rentabilidade e a lucratividade a partir da venda de livros, a oferta é por obras de fácil apreensão, que não exijam um nível de fruição muito aprofundado. Visto que o foco deste artigo não é levar em conta o mérito ou o demérito de tais produções, mencionamos apenas que a luta das instâncias de produção erudita pela preservação de seu capital cultural foi (e ainda é) muito intensa. Ao lado dessas instâncias, segundo Bourdieu (2015), encontra-se o sistema de ensino que ocupa uma posição de reprodução social, ao desempenhar primeiramente uma função de reprodução cultural. Isso se dá pelo fato de as ins-

1 A economia das trocas simbólicas é uma reunião de materiais desenvolvidos por Pierre Bourdieu, organizado por Sérgio Miceli, publicação da ed. Perspectiva: São Paulo, no ano de 1974. 
tituições de ensino requererem de seus alunos habilidades linguísticas e culturais para apreensão dos bens culturais, as quais não lhes foram concedidas no período escolar. Assim, ao difundir literatura canonizada, a escola não oferece ao aluno-leitor obras que estejam dentro do seu horizonte de expectativas, levando-o à busca de produções que lhe propiciem significativo processo de identificação.

A produção intensiva e maciça de uma literatura que cativa cria nos indivíduos o hábito de compra, e, por conta de tal hábito, tornam-se consumidores e colecionadores de informação (WELLERSHOFF, 1970). Ao encontrar nos jovens um público tão assíduo, o investimento do mercado do livro em obras que atendam a esse nicho se tornou ainda mais intensivo e criativo. De acordo com Eric Hobsbawm $(1995)^{2}$, o ano de 1970 - ano de estabelecimento da indústria cultural - foi o período em que mudanças radicais ocorreram no núcleo familiar convencional, o que atingiu diretamente os jovens. Nessa época, acontece o aumento de uma cultura especificamente juvenil, a juventude consegue autonomia como camada social desassociada da ideia de ser apenas uma etapa para chegar à vida adulta. Os jovens se enxergam no estágio final do pleno desenvolvimento humano e, ao seu lado, surge o adolescente consciente de si mesmo, reconhecido pelos que produzem bens de consumo. 0 herói dos jovens passa a ser aquele cuja vida finda no

2 Primeira edição 1994. 
momento em que termina sua juventude; os valores patriarcais são por eles considerados retrógrados e por isso são negados e afrontados. 0 rock e o blue jeans passam a ser marcas dessa nova camada social e permitem a ela uma identificação nacional e mundial. Ademais, a juventude das classes alta, média e baixa começam a intercambiar sua cultura.

Por conquistar seu espaço no cenário econômico, o jovem, então, detém grande poder de compra. A base da Revolução Cultural passou a ser a cultura da juventude, acarretando transformações de condutas e práticas e na forma como artes comerciais e lazer são usufruídos. Sua visibilidade adveio da representação de uma massa com alto poder de compra e, também, pelo fato de as novas gerações de adultos terem sido marcadas por essa cultura juvenil autoconsciente, visto que fizeram parte dela. Esse novo estilo desperta, além da rejeição aos valores até então vigentes, a busca pela liberdade de poder fazer o que bem entender (HOBSBAWM, 1995).

\section{Os jovens leitores e a distopia}

A literatura entra nesse movimento do mercado - as editoras trabalham com a materialidade de suas produções para alcançar seu público-alvo e os autores escrevem diretamente a ele. Martha (2010) 
afirma que os chamados "temas de fronteira"3 permitem um processo de identificação entre jovens e crianças com os indivíduos do mundo ficcional ao proporcionarem aos leitores a oportunidade de refletir a respeito de "sua condição e elaborar sua imagem enquanto seres-no-mundo" (MARTHA, 2010, p.1). Isso acontece depois do abandono da literatura higienizada, que procurava suprimir qualquer tipo de sofrimento e crueldade, idealizando a infância e a juventude, vertentes moralistas que eram muito úteis à escola e à família. Consolida-se uma perspectiva que desnuda e retrata os conflitos psicológicos vividos pelos indivíduos dessa fase, a ambientação inóspita e a experienciação de sentimentos e emoções violentas (MARTHA, 2010).

Em estudo sobre a literatura juvenil distópica, Cássia Farias (2007) assegura que, no contexto contemporâneo, é na adolescência que o sujeito começa a ser realmente inserido na sociedade e passa, então, a sofrer com aspectos que antes não lhe afetavam tanto - ao menos, não de maneira consciente. Sofre com pressões e inquietações advindas do momento sócio histórico atual além de aumentarem as influências e imposições da família e da escola na intenção de que esse indivíduo conquiste autonomia e independência

3 Segundo Martha (2010, p.1), "temas de fronteira são situações-limite, que configurem, no plano ficcional, etapas da evolução vividas pelo ser humano e que possam traduzir modos de preservação da identidade individual e sociocultural sem abster-se da participação do processo de universalização". 
e, consequentemente, maturidade. É nessa fase que a autoridade parece opressiva, descortinam-se diante do leitor situações que lhe geram confusões e questionamentos - não tão novo para regalias e confortos da infância, mas não suficientemente maduro para aproveitar os privilégios que a vida adulta pode oferecer.

Martha (2010) aponta que, tanto a adoção de personagens jovens e adolescentes, rodeados de personagens secundários como mãe, pai, parentes, amigos, professores para desempenhar funções, às vezes, desagradáveis na estrutura da narrativa, como a construção das personagens que valorizam a adolescência e a juventude como fases plenas de valor e significado, e não apenas como uma preparação para a vida adulta, atraem a atenção dos leitores, gerando reconhecimento de tais personagens elaboradas "como portadoras de uma identidade própria e completa" (MARTHA, 2010, p.20).

Thiago Valente (2015), respaldado por Aguiar (2014), afirma que a produção da literatura infantil e juvenil, ao fazer uso de recursos estéticos, desenvolvendo-os sob a perspectiva do jovem e da criança, cresce no cenário da literatura geral, colocando em cena esse novo público:

Tal produção se desenvolve no cenário da literatura em geral, valendo-se, portanto, das representações e dos recursos estéticos consagrados, ao mesmo tempo em que parece marcar um leitor específico, que vai se 
desenhando no texto, e com o qual o narrador dialoga. Esse leitor implícito, afinado com os jovens que vivem no mundo de hoje, traz, assim, para a diegese, a voz desse novo público. (VALENTE, 2015, p.2)

Enxergar o jovem e o adolescente sem lentes utópicas que mostrem uma realidade que não é real, como a literatura infantil e a juvenil costumavam fazer, não é mais uma possibilidade; o estudioso aponta que seria uma anacronia e até mesmo uma insensatez enxergar no jovem contemporâneo a possibilidade de uma utopia, segundo senso comum pós-moderno (VALENTE, 2015, p.6). Não que, portanto, a distopia seja meramente o oposto de utopia. Para uma melhor compreensão desse tipo de narrativa, Marilena Chauí (2008, s/p) afirma que "[a] utopia nasce como um gênero literário", no século XVI, retratando a sociedade perfeita e feliz - de acordo com a pesquisadora, seria um "não lugar" que vem como negação da sociedade real, ou como uma visão de um futuro em que os aspectos negativos (desigualdade, injustiça, exploração) são suprimidos, ao passo que o que há de positivo (conhecimento, arte, ciência) é desenvolvido.

Todavia, a pesquisadora assegura que nenhuma utopia teve influência no percurso da história devido ao seu realismo, mas sim pela negação profunda das fronteiras do real instituído. "Referindo-se à articulação entre os elementos próprios do discurso e da narrativa utópicos e o totalitarismo, alguns autores falam em distopia, o topos dilacerado e infeliz. As 
obras de distopia nos levam do sonho ao pesadelo" (CHAUÍ, 2000, s/p - grifos da autora). Referente à distopia, Leonir Cardoso Hilário (2013) aponta que tal tipo de narrativa se configura, pela perspectiva da teoria crítica da sociedade, como um mecanismo de análise severa da modernidade, a "distopia em particular, emerge como dispositivo de análise radical da sociedade, cujo objetivo é analisar os efeitos de barbárie que se manifestam em determinado tecido social" (HILÁRIO, 2013, p.201). Para essa mesma teoria crítica, a obra literária possui a capacidade de gerar efeitos de análise relativos às transformações sociais e suas aplicações ao nível subjetivo, político e ético. Assim, compreendemos a afirmação de Hilário (2013) quanto a distopia oferecer elementos para o pensamento crítico sobre a contemporaneidade, em especial, sobre a segunda metade do século XX e começo do século XXI.

As narrativas distópicas, muitas vezes, acercam-se da ficção científica em razão de sua forte ligação com tempos futuros, com a ciência; porém, enfatizam a função política, valorizando sobretudo a crítica social e a conscientização dos leitores. A ficção científica, por sua vez, embora apresente um aparato "científico", visa, em essência, à confrontação com o outro, à busca e ao encontro com a alteridade. A distopia pode ser entendida como uma construção que tem como base o fracasso do ideal da sociedade perfeita esperada como futuro. A perspectiva de um mundo melhor 
- a busca por uma ordem social ideal - parece inerente ao ser humano. No entanto, essa noção enfraquece e cede lugar à visão desalentada quanto ao futuro. A ficção científica mostra-se apropriada para questionar e denunciar a falência dos sonhos na construção de um mundo confiável, antecipa a destruição da realidade perfeita, anunciando a distopia, e nasce pela constante busca do homem por um espaço melhor em outro lugar.

Para Hilário, o texto distópico é uma espécie de aviso sobre algo ruim prestes a acontecer, uma maneira de alertar sobre um perigo iminente que precisa ser controlado e seus efeitos devem ser inibidos mesmo que já estejam em curso (HILÁRIO, 2013). Diante disso, aponta que tal gênero possibilita ao leitor refletir sobre as questões que envolvem o sujeito em todas essas esferas, propiciando a discussão sociocrítica que garante ser a literatura não apenas um reflexo mecânico da sociedade, mas uma maneira de experienciá-la, além de possibilitar a análise crítica dos componentes sociais (HILÁRIO, 2013). A "estratégia" da distopia para alcançar tal efeito é usar o assombro para enfatizar as práticas e tendências contemporâneas que podem privar, em algum momento, o indivíduo de sua liberdade. A certa altura de suas discussões, o pesquisador procura definir o que é a distopia: 
Etimologicamente, distopia é a palavra formada pelo prefixo dis (doente, anormal, dificuldade ou mal funcionamento) mais topos (lugar). Num sentido literal, significa forma distorcida de um lugar. Neste caso se referindo a um curso anormal e inesperado de acontecimentos que compõem determinada forma social. Acrescente-se a isso a distopia não é o contrário da utopia, não se configurando enquanto uma antiutopia. Pois ela não é avessa a todo e qualquer tipo de utopia, como se esta fosse essencialmente perigosa e necessariamente descartável. (HILLÁRIO, 2013, p.205-206, grifos do autor)

Pelo fato de as distopias alertarem para um futuro pior, elas podem ser confundidas com apologias ao declínio da sociedade, todavia, como já mencionado anteriormente, elas funcionam como uma denúncia dos efeitos negativos que diferentes instâncias podem gerar, alertando quanto ao que pode ser feito no presente, e não podem ser confundidas com ficções futuristas. Outra de suas características marcantes é o exagero, a potencialização, a caricatura de situações e ações, em que "as criações supostamente emancipatórias paradoxalmente convertem-se em instrumentos de dominação" (HILÁRIO, 2013, p.207).

Não se pode esquecer que esse teor de crítica social tem por trás os imperativos mercadológicos, visto que essa temática da literatura juvenil é um dos mais recentes investimentos da indústria do livro. Ao dirigir-se diretamente ao público pretendido, o mercado investe maciçamente em obras cujos protagonistas são sujeitos quase ingressando na idade adulta; a 
narrativa é iniciada na iminência de um evento importante, o que gera uma reviravolta na vida dessa personagem, transformando a maneira como se relaciona com os demais, com a sociedade e consigo (FARIAS, 2017). Daniel, o protagonista da obra analisada, começa a história em seu 13o aniversário e ganha três grandes presentes, um deles - o mais importante para o adolescente - desnuda um ponto de destaque no livro.

Dentro desse mercado e dessa nova produção distópica, duas vertentes podem ser percebidas:

uma que consegue se desvencilhar do plano de fundo e, embora partindo de fatos e contextos da realidade vivenciada ou percebida pelos jovens leitores contemporâneos, permite à ficção aflorar como elemento estético de destaque na obra; outra que, embora tente um tratamento literário mais adequado ao jovem, não consegue realizar um bom nível ficcional, ficando presa a referências históricas e sociais mais imediatas. (VALENTE, 2010, p.71)

Considerando a distopia como uma temática da literatura juvenil que adverte quanto ao provável declínio da sociedade caso nenhuma providência seja tomada, a seção seguinte traz uma análise textual de abordagem e temática que se enquadra na categoria de distopia, apresentando pontos que mostrem a diminuição da distância entre texto e leitor juvenil de maneira que haja um processo de identificação desse adolescente real com o da ficção. 
2. Ventania Brava e a distopia de um futuro governado por adolescentes

A obra analisada foi publicada em 2015 pela editora SESI-SP, inserida na coleção "Quem lê sabe por quê" e escrita por Luiz Bras". Segundo informações que constam na orelha do livro, o autor nasceu em Cobra Norato, pequena cidade da mítica Terra Brasilis, cidade onde a história é ambientada. Cobra Norato, segundo posfácio presente na edição, "não se parece muito com as outras cidades do planeta. Muito instável, bastante temperamental, seu humor está sempre mudando. [...] 0 amor e o horror são os extremos de sua personalidade inquieta" (BRAS, 2015, p.194). Seu nome é oriundo de um monte de mesmo nome sobre o qual a cidade foi construída e acompanhado por uma história mítica que afirma ser ele localizado, a princípio, no centro do estado do Pará, mas misteriosamente some e aparece no Mato Grosso do Sul. Relata Luiz Bras que ao lado do morro vivia uma tribo tapuia, responsável por dar nome ao local, oriunda de uma antiga lenda dos povos da floresta amazônica que conta a história de dois irmãos gêmeos nascidos enfeitiçados em forma de serpentes. 0 irmão, Cobra Norato, bom coração, acaba por matar sua irmã Maria Caninana, má e violenta. Cobra Norato assume a for-

4 Nelson Luiz Garcia de Oliveira é escritor brasileiro nascido em Guaíra, SP, em 1968. Conhecido também por Nelson de Oliveira e por Luiz Bras. 
ma de homem durante a noite e vai até a cidade para cantar, dançar, beber, conversar e paquerar, porém, é obrigado a voltar para sua pele de cobra de madrugada. Seu grande sonho é se tornar homem definitivamente. $\mathrm{O}$ morro foi batizado em homenagem a esse bom rapaz.

É interessante mencionarmos que o autor narra, no posfácio, toda essa situação como se ela de fato fosse real, como se essa cidade realmente existisse. Essa "realidade" se intensifica ao aliá-la à informação da orelha do livro que comunica ter Luiz Bras nascido na cidade de Cobra Norato. Dessa maneira, ao final da narrativa, ainda que o escrito assuma a voz, o leitor permanece inserido numa história - tendo ele consciência disso ou não. 0 público é transportado de uma história do futuro para uma lenda do passado, cuja ligação é a cidade, onde coisas misteriosas e inesperadas acontecem. Assim como em Cobra Norato da lenda, a cidade da história é um lugar onde situações surpreendentes se desenrolam, onde uma ventania misteriosa surge para abalar o dia dos cidadãos e transformar sua realidade. Os fatos narrados transcorrem no ano de 2090

e agora os jovens administram o mundo. Todos os políticos e empresários têm menos de dezoito anos. Até mesmo o presidente da república é um adolescente. Os adultos foram banidos dos cargos importantes por absoluta incompetência em governar o mundo. Atualmente eles ficam em casa ou viajando, aproveitando as prolongadas férias. 0 planeta e as pessoas vivem 
em paz. Não há mais guerras nem devastação ambiental. (2015, orelha do livro)

Adolescentes governam o mundo com muito mais prudência e maturidade, e, em 2090, não é apenas isso que está diferente, a tecnologia avançou muito - carros não precisam mais de motorista, as pessoas podem comprar rostos novos, as inteligências artificiais são programadas para se portar como verdadeiros seres humanos e inúmeros outros avanços. Daniel, o protagonista dessa obra, completa 13 anos e ganha três presentes importantes: assume o cargo de presidente da empresa de reciclagem em que trabalha, ganha seu próprio carro e um rosto novinho e permanente - esse é o presente pelo qual Daniel mais ansiava, um rosto perfeito, sem espinhas, sem defeitos; entra em cena, então, a vaidade. Tudo vai bem, a não ser por uma ventania brava que assola a cidade há meses e que desperta a curiosidade dos moradores, mas ninguém sabe de onde vem e nem quando se vai, um vento como esse não assola nenhuma outra cidade do Brasil, nem do mundo. A ventania começa a ficar cada vez mais violenta, a ponto de levantar crianças e adolescentes pelos ares e fazê-los sumir. Em certa altura, Daniel e Sofia, sua namorada, estão no carro e, levados pela ventania, percebem que não se trata apenas de um fenômeno meteorológico; seguem o que parece ser uma serpente amarelada presente na ventania até uma festa que acontece na 
cidade. A ventania invade o local, e coisas assombrosas intercorrem, parentes mortos voltam à vida, obras de arte perdidas em incêndios ou roubadas aparecem diante dos olhos dos convidados, toda espécie de desejo profundo, mesmo que esquecido, começa a se realizar.

Nesse momento, Sofia é levada a um lugar denominado Paisagem, onde a ventania se torna Ventania e todos os segredos do universo lhe são revelados, ao passo que Daniel tem seu rosto artificial transformado em rosto verdadeiro. Sofia sonhava com o conhecimento, Daniel, com um rosto bonito. É na Paisagem que é declarado que a ventania se trata de uma espécie de gênio da lâmpada, um brinquedo perdido que concede os desejos mais ocultos. Esse brinquedo foi desenvolvido por uma raça de alienígenas muito mais inteligentes que os seres humanos, considerados míseras formigas, e que vivem a muitos anos luz do planeta Terra. No último capítulo, nos é revelado que esses alienígenas não sofrem com guerras, não conhecem rancor ou ódio, também não dormem, não cantam, não dançam, não se apaixonam e não amam.

0 narrador onisciente conversa com o leitor por toda a narrativa, oferecendo pistas e chamando sua atenção para o que está por vir. Inicia, no capítulo zero, uma espécie de introdução, um tipo de prefácio, contando ao público a respeito do gênio da lâmpada da história de Aladim, um gênio que concede desejos, mas cuja história já não é mais conhecida em 2090. 
Essa "introdução" já dá indícios de que algo diferente irá acontecer nessa história: “a verdade é que o gênio da lâmpada existe. Mas o grande problema é que ele é muito diferente - e mais perigoso - do que a gente imaginava" (BRAS, 2015, p.12-13). Ademais, é revelado o teor da reflexão proposta por essa distopia, "[a] gente costuma ser bastante egoísta quando quer algo. Egoísta e vaidoso" (BRAS, 2015, p.11). Uma das maiores críticas feitas é em relação à vaidade e, para isso, diferentes mecanismos são usados - por exemplo, um adolescente desabafa em um restaurante sobre os efeitos negativos da ventania, todos ao redor estão preocupados com o conteúdo de sua fala, enquanto Daniel, ao reparar que a máscara de rosto dessa personagem não é permanente e está descolando, reflete sobre a aparência física do menino, sobre os defeitos de seu rosto verdadeiro; logo em seguida, Sofia menciona uma reflexão do livro bíblico, Eclesiastes, sobre tudo ser vaidade.

A estrutura narrativa adota situações do mundo adulto vividas por sujeitos na faixa dos 12 e 13 anos, cujo ápice de maturidade é aos 15 e a aposentadoria aos 20. Termos do mundo adulto e do mundo juvenil caminham lado a lado. Se, por um lado, as personagens deparam-se com situações, profissões e problemas adultos, por outro, o leitor se defronta com uma linguagem próxima à falada, descontraída, com termos como "pra" e nomes como o da empresa em que Daniel é presidente, a saber, "Abracadabra Reci- 
clagem Inteligente S. A.", relativa ao universo jovem. Dessa maneira, o narrador aproxima de si seu leitor, mas também lhe oferece temáticas e vocábulos que vão além e o tiram de sua zona de conforto.

A juventude é exaltada em certa medida enquanto a vida adulta e a velhice são tratadas como desagradáveis e ociosas, quase como se a vida ali findasse. Contrariamente ao que é apregoado antes da Revolução Cultural, como aponta Hobsbawm (1995), é após ela que a juventude começa a ser vista como um estágio de pleno desenvolvimento humano, em que a vida do herói começa e termina na sua juventude. 0 narrador de Ventania Brava garante que " [a] juventude é muito curta, a velhice é muito longa (BRAS, 2015, p.23)” e que

[...] é na juventude que a poesia acontece com a máxima intensidade. À medida que os jovens vão envelhecendo, eles vão perdendo o contato com essa manifestação tão sublime. Vão ficando mais irônicos. Mais cínicos. (BRAS, 2015, p.25-26)

A sublimação dessa fase da vida, como se ela pudesse ser a solução para os maiores problemas sociais e econômicos, torna os velhos cada vez mais distantes da beleza da vida. Segundo a personagem Daniel, os velhos perderam o contato com a poesia, definida pelo narrador: "Poesia significa beleza, equilíbrio, arte. Poesia significa harmonia física e espiritual" (BRAS, 2015, p.108). 0 interessante é que mesmo 
tratando os adultos como indivíduos que só dão "dor de cabeça”, algumas considerações são feitas, como se detalhes importantes fossem sendo despercebidamente perdidos: ainda no capítulo um, Daniel critica um adulto que dirige um carro e só causa transtorno (os carros de 2090 já não necessitam mais de motorista), contudo esse automóvel é "estonteantemente vermelho" (BRAS, 2015, p.28), e Daniel vê poesia nessa cena e reflete sobre todo o trânsito de então ser cinza; há apenas cores frias, os tons quentes sumiram simplesmente.

No desenrolar da trama, percebemos que a tecnologia e a inversão dos papéis sociais trouxeram de fato muitos benefícios, mas com eles vieram a diminuição da relação interpessoal e a permanência da vaidade. Contextualizando o leitor sobre a situação da época da história, o narrador conta que "Face a Face era a rede social do momento. Mais da metade da população passava mais da metade do dia conectada a ela" (BRAS, 2015, p.42), trata-se de uma grande ironia a rede social se chamar "face a face", oferecendo conversa e relacionamento virtuais. Essas são marcas deixadas que podem levar o público a uma reflexão acerca do caminho que a sociedade tem tomado e, como característico da narrativa distópica, alertá-lo quanto a esse caminho.

Outro ponto de relevância na história é Daniel conseguir ouvir vozes em meio à ventania - no final descobre-se que ela é uma máquina muito sofistica- 
da, formada por milhões de bilhões de trilhões de nano-robôs autônomos programados para funcionar em sincronia - como se ela estivesse tentando se comunicar. Na realidade, ela não quer nada com a raça humana, mas estando na Terra, faz gravações sobre o comportamento humano para dividir com seus criadores quando conseguir retornar para casa. Daniel fica, em vários momentos, tentando entender o que as vozes da ventania dizem, até perceber que são trechos de músicas de bandas famosas dos anos 1970 . As mensagens que a ventania passa, aparentemente, referem-se unicamente a sua própria ação. A primeira delas se constitui de trechos da música Across the universe, dos Beatles, como se informasse sobre sua viagem e sobre suas palavras soltas no ar. A seguinte é composta de versos de Space oddity, de David Bowie, também do século XX, para informar que em breve ela partirá. Dessa maneira, o adolescente leitor tem acesso a grandes sucessos do século passado, ainda que apenas na textualidade.

Depois do nono capítulo - que conta sobre a partida da ventania e sobre Cobra Norato voltar à calmaria por um curto período de tempo, já que repórteres de todos os cantos do mundo logo chegarão à cidade para entrevistar os mortos que voltaram a vida -, o último capítulo faz um pequeno retorno ao dia em que a ventania partiu da cidade em direção ao espaço. Nesse capítulo, o narrador apresenta ao leitor "mais um personagem importante dessa história" (BRAS, 
2015, p.183), um senhor cujo nome é Efraim e que foi a última pessoa a ver a ventania. Um homem de mais de cem anos que se encontra sozinho em uma das escadas de um instituto de biotecnologia e desfruta de uma xícara de chá enquanto contempla a perfeição de seus membros biônicos, "Efraim perdeu o braço esquerdo trinta anos atrás, durante a revolução armada que tirou os adultos do poder" (BRAS, 2015, p.185). De repente, esse homem ouve um sussurro, mas não encontra ninguém além de duas inteligências artificiais entediadas que jogam xadrez. Efraim percebe que o sussurro vem da ventania e finalmente entende que se despede em vários idiomas diferentes e lhe responde com um "adeus".

Por que um homem de mais de cem anos foi o escolhido para ser o último a ver essa maravilha tecnológica? De acordo com as outras personagens, a vida adulta é chata e sem graça. Estariam elas erradas em alguma medida? Seria, talvez, mais uma reflexão proposta pelo narrador quanto a importância dessa fase da vida? 0 fato é que se trata de uma personagem descrita como importante e que traz um grande estranhamento ao leitor, visto que, durante todas as páginas do livro, os adolescentes imperam e todos os adultos se mostram mesquinhos e inconsequentes, mas a última pessoa, a que parece mais centrada e ter maior compreensão da comunicação da ventania é um senhor de mais de cem anos. 
Os aspectos discutidos são apenas alguns dos pontos que revelam ser Ventania brava uma narrativa distópica que intenciona levar o leitor a uma reflexão acerca da vida, da vaidade, do poder e influência da juventude, do caminho sem volta em direção à tecnologia; independente de quem tem o controle, seja adulto, seja adolescente, a vaidade impera e o caminho é o mesmo - a raça alienígena, antiga e detentora de grande poder e conhecimento tecnológico, não possui o que há de mais humano, tanto ruim como bom, e avançar em direção a isso pode ser um caminho sem volta para os homens.

\section{Considerações finais}

As marcas textuais levantadas no livro Ventania Brava configuram aspectos de uma narrativa distópica, que circula e é consumida por uma audiência juvenil, proporcionando aos seus leitores um processo de identificação enquanto seres-no-mundo e de reflexão acerca das possíveis consequências de determinadas escolhas. A investigação, baseada nos estudos sobre o mercado e a literatura juvenil, mais especificamente sobre a temática da distopia nessa produção, revela que as construções textuais analisadas exigem inferências por parte do leitor e fazem referências a narrativas externas ao texto, o que obriga o leitor a refletir além, não só a respeito daquilo para o qual 
sua atenção é chamada, mas também para o reconhecimento dessas referências extratextuais.

Concluímos que a distopia é de fato uma escolha de mercado e de autores que acatam as expectativas de jovens leitores, os quais buscam um senso de pertencimento. Os interesses mercadológicos que encontram nessa audiência um nicho de alta rentabilidade investem maciçamente em tais produções. A obra Ventania Brava, de Luiz Bras, é, pois, uma ficção distópica, cuja construção da narrativa aponta para um enredo repleto de situações de um futuro enriquecido pela imaginação do autor, onde carros andam sem motorista, crianças dominam o mundo, rostos artificiais substituem os verdadeiros e o artificial é mais perfeito que o natural. Com um narrador onisciente, dirige-se a jovens leitores, trazendo conceitos, ideias e referências do mundo adulto que exigem um leitor capaz de fazer inferências e produzir sentimentos e sensações advindas de alertas e comentários.

Finalmente, esperamos que esse artigo contribua, em alguma medida, para os estudos sobre a literatura juvenil e, no caso, a distópica que, apesar de ter conquistado seu espaço no cenário da literatura geral, ainda tem um árduo caminho para trilhar e preconceitos para romper, e que, por isso, trata-se de uma literatura pouco estudada merecedora de espaço e longe de ser uma discussão exaurida. 


\section{Referências}

BOURDIEU, Pierre. A economia das trocas simbólicas: Introdução, organização e seleção Sergio Miceli. Tradução de Sergio Miceli, Silvia de Almeida Prado, Sonia Miceli e Wilson Campos Vieira. 8. ed. São Paulo: Perspectiva, 2015. CHAUÍ, Marilena. Notas sobre utopia. Ciência e Cultura, São Paulo, v.60, 2008. ISSN 2317-6660. Disponível em: http://cienciaecultura.bvs.br/scielo.php?script=sci arttext\&pid=S0009-67252008000500003. Acesso em: 30 set. 2018.

FARIAS, Cássia. Um estudo sobre o corpo na literatura juvenil distópica. In: Anais do VIII Seminário dos Alunos dos Programas de Pós-Graduação do Instituto de Letras da UFF - Estudos de Literaturas. n. 1, p. 95-105, 2017. Disponível em: http://www.anaisdosappil.uff.br/index.php/VIIISAPPIL-Lit/article/view/696/490. Acesso em: 30 set. 2018. HILÁRIO, Leomir Cardoso. Teoria crítica e literatura: distopia como ferramenta de análise radical da modernidade. Anu, Lit., Florianópolis, v.18, n.2, p. 201-215, 2013. ISSNe 2175-7917. Disponível em: https://periodicos.ufsc.br/ index.php/literatura/article/view/27842. Acesso em: 28 set. 2018.

HOBSBAWM, Eric. Era dos extremos: o breve século XX 1914-1991. Tradução de Marcos Santarrita. 2. ed. São Paulo: Companhia das Letras, 1995, p. 314-336.

MARTHA, Alice Áurea Penteado. Narrativas de língua portuguesa: temas de fronteira para crianças e jovens. In: Língua portuguesa: ultrapassar fronteiras, juntar culturas. Universidade de Évora, p. 1-22, 2010. ISBN: 978-97299292-4-3. Disponível em: http://www.simelp2009.uevora.pt/pdf/slt59/02.pdf. Acesso em: 28 set. 2018.

RABECCHI, Ana Lúcia Gomes da Silva. Utopias e distopias: conflitos paradigmáticos. Cadernos Cespuc, Belo Horizonte, n.19. 2010. Disponível em: http://periodicos.pucminas. 
br/index.php/cadernoscespuc/article/view/7823. Acesso em: 28 set. 2018.

VALENTE, Thiago Alves. Utopia, distopia e realidade: um novo verismo na literatura para jovens. Letras e Hoje, Porto Alegra, v. 45, n.3, p.70-74, jul./set. 2010. Disponível em: http://revistaseletronicas.pucrs.br/ojs/index.php/fale/ article/viewFile/8123/5812. Acesso em: 28 set. 2018.

VALENTE, Thiago Alves. Brandão e Bernardo: narrativa, filosofia e ficção. In: Abralic. XIV Congresso Internacional Fluxos e correntes: trânsitos e traduções literárias, Belém, 2015. Disponível em: http://www.gustavobernardo.com/ brandaobernardo.pdf. Acesso em: 30 de set. 2018.

WELLERSHOFF, Dieter. Literatura, mercado e indústria cultural. Tradução de Teresa Balté. Humboldt, Hamburgo, 1970, p.44-48. 